\title{
O desenvolvimento participativo e sustentável como inovação social ${ }^{1}$
}

\author{
The participatory and sustainable development as social innovation \\ El desarrollo participativo y sostenible como innovación social
}

Recebido: 11/23/2021 | Revisado: 11/29/2021 | Aceito: 11/30/2021| Publicado: 12/04/2021

Pedro Arturo Rojas Arenas

ORCID: https://orcid.org/0000 000292791174 Universidade do Estado do Rio Grande do Norte, Brasil E-mail: arturoarenas@uern.br

Adriano Menino de Macêdo Júnior

ORCID: https://orcid.org/0000-0001-6367-1088

Universidade do Estado do Rio Grande do Norte, Brasil

E-mail: adrianomenino2016@gmail.com

\begin{abstract}
Resumo
O texto apresenta um breve diagnóstico da sociedade contemporânea, destacando os desafios e oportunidades com os quais se confrontam os estados nacionais. Descreve a crise da sociedade moderna industrial e a emergência de uma nova ordem social na qual o desenvolvimento sustentável torna-se uma questão vital. A seguir reflete sobre o conceito desenvolvimento humano. $\mathrm{O}$ autor considera a participação como o aspecto mais relevante do desenvolvimento. Nessa perspectiva, afirma que a participação efetiva dos indivíduos e das comunidades se faz possível através da organização, promoção e aperfeiçoamento dos recursos humanos, isto é: através de um processo essencialmente educativo. Processo educativo que incorpora ciência e tecnologia para o desenvolvimento autônomo das comunidades. De outra parte, considera que o desenvolvimento humano só pode ser realizado sobre o patamar da justiça social que, por sua vez, se operacionaliza através da consulta. O processo da consulta permite que os indivíduos e as comunidades identifiquem seu próprio modelo de desenvolvimento. O texto finaliza afirmando que a aceitação do conceito de cidadania mundial constitui o correlato indispensável deste processo social contemporâneo; sem esse tipo de ética global, as pessoas não poderão se tornar participantes ativos e construtivos no processo mundial de desenvolvimento sustentável.
\end{abstract}

Palavras-chave: Sociedade contemporânea; Participação e desenvolvimento; Educação ciência e tecnologia; Processo consultivo; Justiça social; Cidadania mundial; Ética mundial e desenvolvimento sustentável.

\begin{abstract}
The text presents a brief diagnostic of contemporary society, highlighting the challenges and opportunities confronting the national states. It describes the crisis of modern industrial society and the emergence of a new social order in which the sustainable development becomes a vital issue. To follow reflecting on the concept human development and, from this perspective, considers the participation as the most important aspect of development. The author assumes that the effective participation of individuals and the community is possible through the organization, promotion and improvement of human resources, that is, through an inherently educational process. Educational process what incorporate alternative science and technology for sustainable development in the communities. On the other hand, he explains that the human development can only be performed on the level of social justice that is tailored by making decisions based on consultation. The process of consultation ought to be promoted with the purpose of achieved the effective participation of the individuals as of the communities in decision-making of your own model of development. In conclusion, the author suggests that the acceptance of the concept of world citizenship is the indispensable correlate of this contemporary social process; without this type of global ethic, the people may not become active participants and constructive in worldwide process of sustainable development.

Keywords: Contemporary society; Participation and development; Education, science and technology; Consultation process; Social justice; World citizenship; Ethics and global sustainable development.
\end{abstract}

\section{Resumen}

Este artículo presenta un breve diagnóstico de la sociedad contemporánea, destacando los desafíos y oportunidades con los cuales se confrontan los estados nación. Describe la crisis de la sociedad moderna industrial y la emergencia de una nueva orden mundial en la cual el desarrollo sustentable se torna una cuestión vital. A continuación, aborda el concepto de desarrollo humano. El autor considera "la participación" como el aspecto más importante del desarrollo.

\footnotetext{
${ }^{1}$ Texto aprovado pela Comissão Científica da 21st WFSF World Conference, Bucharest, Romania, June, 26th-28th of 2013. Tema Central do Evento: Global Research and Social Innovation: transforming futures. Subtema: Complex, integrative and holistic future. Em novembro de 2021, o autor atualizou o texto incluindo breve menção do World Economic Forum e da Conferencia das Nações Unidas sobre mudanças climática - COP-2026. Finalmente, incorporou novas referências
} 
En esta perspectiva, afirma que la participación efectiva de los individuos y de las comunidades se hace posible a través de la organización, promoción y cualificación de los recursos humanos: lo que constituye un proceso esencialmente educativo. Proceso educativo que incorpora ciencia y tecnología para el desarrollo autónomo de las comunidades. De otra parte, considera que el desarrollo humano solamente puede ser alcanzado sobre la base de la justicia social. La justicia social se puede realizar sobre el suporte de la consulta. El proceso de consulta permite que los individuos y las comunidades identifiquen el modelo de desarrollo más adecuado para las comunidades locales. El texto termina afirmando que la aceptación del principio de ciudadanía mundial es indispensable para concretizar este proceso en la sociedad contemporánea. Sin este tipo de ética global, las personas y las comunidades no pueden cumplir un papel activo y constructivo en el desarrollo sustentable.

Palabras clave: Sociedad contemporánea; Participación y desarrollo; Educación, ciencia y tecnología; Proceso consultivo; Justicia social; Ciudadanía mundial; Ética mundial y desarrollo sustentable.

\section{Introdução}

Considerando exclusivamente o desenvolvimento do processo produtivo, a sociedade moderna caracteriza-se pelo uso da máquina, a produção em série e a presença do trabalhador assalariado. "A sociedade pós-moderna ou contemporânea se define a partir de uma nova e substancial transformação da estrutura e dinâmica das forças produtivas da vida humana” Richta (1977). Nesta sociedade observamos transformações no nível do objeto de trabalho, fontes de energia, médios de trabalho e na própria força de trabalho. Desenvolvem-se as matérias primas artificiais, o uso da energia nuclear, a incorporação do computador na produção e uma demanda cada vez maior por trabalhadores especializados. A automação dos processos de trabalho nos três setores do sistema econômico constitui a característica técnica distintiva da sociedade pós-moderna, entanto que, a mecanização faz referência à sociedade moderna, de forma predominante. Toffler (1980). ${ }^{2}$

Berman (1982) na obra Tudo que é sólido desmancha no ar, mostra como a tragédia "Fausto" do Goethe é típica da modernidade. No entanto, atingir o desenvolvimento com justiça social continua sendo o maior desafio da sociedade contemporânea. Este ideal, associado a uma visão de prosperidade de toda a humanidade, constitui-se uma importante força motivadora das atividades desenvolvidas pelos gestores de processos inovadores na construção de uma nova sociedade, sejam eles, cientistas sociais, de outras áreas da ciência ou simples cidadãos.

\section{Metodologia}

Para desenvolvermos os objetivos propostos, embasamo-nos numa perspectiva metodológica da pesquisa exploratória, que segundo o teórico Gil (2002, p. 41) se caracteriza como:

[...] Estas pesquisas têm como objetivo proporcionar maior familiaridade com o problema, com vistas a torná-lo mais explícito ou a constituir hipóteses. Pode-se dizer que estas pesquisas têm como objetivo principal o aprimoramento de idéias ou a descoberta de intuições. Seu planejamento é, portanto, bastante flexível, de modo que possibilite a consideração dos mais variados aspectos relativos ao fato estudado. Na maioria dos casos, essas pesquisas envolvem: (a) levantamento bibliográfico; $(b)$ entrevistas com pessoas que tiveram experiências práticas com o problema pesquisado; e (c) análise de exemplos que "estimulem a compreensão."

Com base no supracitado, apresentamos um breve diagnóstico da sociedade contemporânea, destacando os desafios e oportunidades com os quais se confrontam os estados nacionais. Descrevemos a crise da sociedade moderna industrial e a emergência de uma nova ordem social na qual o desenvolvimento sustentável torna-se uma questão vital. Em seguida refletimos sobre o conceito desenvolvimento humano. Assim, classificamos está pesquisa, de acordo com Gil (2002) em exploratória.

\footnotetext{
${ }^{2}$ Outros aspectos importantes sobre a diferença entre a sociedade moderna e pós-moderna são indicadas por CAPRA (1997) no livro Ponto de mutação em que fala das três transições contemporâneas que incluem: o declínio do patriarcado, o esgotamento dos combustíveis fósseis e a mudança dos paradigmas interpretativos da realidade. No entanto, um aspecto essencial que está relacionado com a universalização e a descentralização da vida social humana está ausente no seu esquema interpretativo.
} 
O teórico Gil (2002, p. 44) classifica também a pesquisa científica com base nos procedimentos técnicos utilizados. Assim, o nosso trabalho classifica-se como bibliográfica, que pode ser elaborada e "desenvolvida com base em material já elaborado, constituído principalmente de livros e artigos científicos." Durante o desenvolvimento de todo o manuscrito, recorremos a teóricos e suas obras importantes para embasar a presente pesquisa, teóricos esses como: Richta (1977) "La Civilización en la Encrucijada", Toffler (1980) "A terceira onda", Berman (1982) "Tudo que é sólido desmancha no ar: a aventura da modernidade", Arbab (1986) "El proceso de transformación social”, Pegoraro (1995) "Ética é justiça", Meadows (1978) "Limites do Crescimento".

Conforme observamos no texto de Daltro, M. R, \& Faria, A. A. (2019, p. 223): “A construção do conhecimento científico organiza-se numa multiplicidade, permanentemente desafiada a elaborar modos de leituras da realidade. Esse estudo apresenta o Relato de Experiência (RE) como produto científico próprio às ciências humanas na pós-modernidade”.

Desta forma, a presente pesquisa tem duas fontes de informação: de uma parte que corresponde à revisão dos autores mais reconhecidos na temática e de outra, o que poderíamos chamar de RE - em termos de outros autores denomina-se como "experiências de vida".

\section{A Sociedade Industrial e a Nova Civilização}

O paradigma da sociedade industrial moderna fundamenta-se na formação dos estados nacionais e na consideração de que o desenvolvimento mede-se fundamentalmente como incremento das forças produtivas da sociedade. Este modelo dá um papel preponderante à racionalidade econômica e pretende estabelecer indicadores eminentemente quantitativos para determinar o desenvolvimento dos países ou regiões tais como: renda per capita, produto interno bruto, etc.

A fundamentação filosófica que sustenta este modelo define o ser humano basicamente como um consumidor de mercadorias e como força de trabalho dos processos produtivos. Seu pleno desenvolvimento tem levado, por um lado, à massificação do mercado, do consumo e dos estilos de vida e, por outro, à centralização dos recursos, da riqueza e da tomada de decisões em poucas mãos.

As tendências que se vislumbram no começo deste novo século indicam o esgotamento de um modelo que tem levado a uma crise do sistema econômico mundial com o processo de empobrecimento da maior parte dos habitantes do planeta e o mais acelerado processo de destruição do entorno ecológico. A humanidade está encaminhando seus esforços na construção de uma nova ordem internacional fundamentada na justiça social e no reconhecimento da interdependência global.

Um novo conceito de desenvolvimento expressa-se nos discursos dos líderes das nações e afeta, marginalmente, as políticas das grandes corporações econômicas. Este conceito compreende não só uma visão de rentabilidade ou lucro, senão também fatores associados com o bem-estar social, tais como: emprego, melhoramento da qualidade de vida e proteção do entorno. Um aspecto essencial deste conceito relaciona-se com a participação das comunidades na elaboração e execução de seus planos de desenvolvimento.

Se no modelo industrial, o conceito de desenvolvimento está relacionado com incrementos quantitativos em indicadores econômicos, na nova sociedade, se estabelece a magnitude ou medida do desenvolvimento pelo bem-estar social e pela participação das comunidades na gestão de suas próprias decisões.

Nesse contexto, o desenvolvimento tem como pré-requisito a existência de organizações e a conquista de conhecimentos científicos. As comunidades regionais e locais emergem e reclamam sua autodeterminação. Novos processos educativos, novas formas de geração de tecnologia adequadas, novas instituições sociais estão se gerando desde as regiões. Sem dúvida, esse processo compreende uma nova visão da educação, da ciência e da tecnologia.

Uma das particularidades deste novo processo se expressa na descentralização e individualização. Descentralização na tomada das decisões e dês-massificação da produção e o consumo. De outro lado, a capacitação de recursos humanos eleva 
o nível de análise dos atores e cria as condições para uma mais adequada tomada de decisões fundamentada no processo consultivo.

O processo da consulta, como instrumento para a resolução de problemas e tomada de decisões, substitui a já desgastada democracia. A consulta produtiva pressupõe a consideração de todos os aspectos e de todos os interesses envolvidos. A visão filosófica que fundamenta essa nova visão do desenvolvimento conceitua o homem como um ser criador, de natureza não só material, senão também espiritual.

\section{Políticas de Desenvolvimento Como Experimento Social}

Geralmente os planos de desenvolvimento elaborados pelas entidades nacionais e internacionais realizam-se sobre a base de que a mudança social não precisa de transformações profundas na estrutura da sociedade e limitam-se, no fundamental, a considerar o indivíduo como objetivo central do mesmo. Espera-se que com maior treinamento, assistência técnica e/ou crédito, etc., mudanças significativas no desenvolvimento das comunidades locais e nacionais podem ser atingidas.

De outro lado, os movimentos revolucionários consideram que só uma modificação radical das estruturas, especialmente das relações sociais de produção, através da conquista do poder político, permite a realização de mudanças sociais significativas.

Arbab (1986) afirma:

"Meu ponto de vista é que o desenvolvimento compreende transformações fundamentais do indivíduo e da estrutura social... Vemos a transformação da sociedade humana como resultado de uma complexa série de interações entre mudanças profundas que devem acontecer dentro do indivíduo e intentos deliberados de mudar a estrutura da sociedade. Além disso, não compreendemos a mudança das estruturas sociais meramente como uma mudança política, senão como a mudança total das estruturas mentais, culturais, econômicas e sociais que, incluem uma mudança completa nos conceitos mesmos de liderança e poder político".

\section{Visão Participativa do Desenvolvimento}

Pensar o desenvolvimento participativo e sustentável como inovação social pressupõe uma original perspectiva teórica e prática que está sendo construída em diversos projetos governamentais e, particularmente, de ONGs pelo mundo tudo. As reflexões a seguir, são resultado de uma profunda revisão conceitual e da experiência que teve como pesquisador convidado na Fundación para la aplicación y enseñanza de las ciências, FUNDAEC, no ano de $1988^{3}$

Um aspecto de especial interesse, na elaboração de uma proposta alternativa de desenvolvimento, é a sua compreensão como um processo complexo, em oposição à ideia que considera o desenvolvimento como um pacote que se doa à comunidade. A percepção unilateral e assistencialista do desenvolvimento é superada por uma perspectiva multilateral e participativa.

O desenvolvimento só é possível com a participação efetiva dos indivíduos e das comunidades. Trata-se de uma participação não limitada ao desfrute de certos serviços indispensáveis ou básicos, nem relacionada só com o incremento ocasional da renda e, em caso nenhum, à simples consideração marginal das opiniões dos grupos afetados. Trata-se duma

\footnotetext{
${ }^{3}$ A Fundação para aplicação e ensino das ciências, FUNDAEC, foi estabelecida na Colômbia a partir de 1974 . O propósito principal que motivou os fundadores foi o de encontrar estratégias para um desenvolvimento rural autônomo. Seus fundadores dedicaram seus esforços para a criação do que foi chamada de Universidade para o Desenvolvimento Integral. A Universidade é definida como um espaço social no qual os habitantes de uma região aprendem a desenhar seu próprio caminho de desenvolvimento. Metodologicamente, a Universidade rural foca o estudo dos processos da vida social da população, por exemplo: a produção e comercialização, a educação, a tomada de decisões, o processo de socialização e assim por diante. Ao mesmo, tempo coloca em funcionamento processos paralelos de aprendizagem que incluem a pesquisa ação. Os processos sobre os quais tem se dado maior atenção e em torno do quais se a gerado valiosos conhecimentos são: educação formal não escolarizada, sistemas de produção em pequenas parcelas, agroindústria rural, unidades de apoio à produção e a criação de instituições para o fortalecimento da economia local, tais como: o fundo local, o centro de pesquisa em tecnologia apropriada e limpa, centros de assistência técnica e comercialização.
} 
participação a todos os níveis no processo de desenho e realização dos objetivos de seu desenvolvimento. Essa visão estabelece duas condições básicas, sem as quais não pode dar-se a participação efetiva e autêntica das comunidades:

a. As comunidades devem ter acesso real ao conhecimento mais avançado. No interior dos países é aceito como razoável que as comunidades rurais e as comunidades urbanas periféricas tenham acesso a um tipo de educação de segunda categoria. Muitos currículos das escolas rurais foram elaborados tendo como base o modelo da educação urbana moderna. No entanto algumas instituições estão experimentando novos conteúdos temáticos e novas metodologias adequadas a meio rural e as zonas urbanas marginalizadas. Essas organizações acham que todos os habitantes do campo e da cidade tem direito ao conhecimento mais avançado nas ciências.

a. Devem desenvolver formas organizacionais através das quais possam manter relações, em condições de igualdade $e$ de uma suficiente autonomia frente a poderosas forças que operam do exterior das comunidades. Forças que procuram a submissão da cultura e da economia das comunidades para beneficiar as corporações ou monopólios nacionais e internacionais de produção e comercialização de bens manufaturados.

Entender o desenvolvimento como processo implica também uma nova perspectiva institucional na qual as entidades públicas ou privadas de desenvolvimento se percebem como parte do processo e suscetíveis de constantes reformulações. Mais que agentes externos, serão elementos catalisadores, promovendo a participação plena das comunidades através da consulta. Dessa forma podem sintetizar experiências e conhecimentos, assim como elaborar planos e programas em consenso com a população.

A nova visão do desenvolvimento também compreende estruturas, processos e conteúdos educacionais, buscando superar os esquemas tradicionais baseados no suposto que o conhecimento, assim como a ciência e a tecnologia são originados, sempre, fora das comunidades.

Trata-se aqui de estabelecer novos canais de transmissão e sistematização do conhecimento e da tecnologia, e novos processos de pesquisa, diferentes dos tradicionais ou clássicos. A educação não pode limitar-se só à transferência de informações, mas, encaminhar os seus esforços, principalmente, com o objetivo de elevar o nível de análise da comunidade no que diz respeito aos processos econômicos e sociais que lhe afeta direta ou indiretamente.

\section{Sobre o Conceito Desenvolvimento Sustentável}

A expressão desenvolvimento sustentável foi cunhada no documento Nosso Futuro Comum, publicado em 1987, igualmente denominado Relatório Bruntland, com a seguinte definição:

... O desenvolvimento sustentável é a capacidade de atender às necessidades do presente sem comprometer a possibilidade das gerações futuras atenderem às suas próprias necessidades.

A construção de um modelo de desenvolvimento sustentável passa pela consideração de vários critérios teóricos que devem ser operacionalizados tanto para a realização de pesquisas ou na eventualidade de executar ações ou projetos específicos em um município, distrito, ou comunidade urbana ou rural.

Os critérios básicos de um modelo teórico-operacional de desenvolvimento sustentável podem ser definidos da seguinte forma:

a) o projeto deve ser socialmente justo e essencialmente participativo;

b) o projeto deve considerar a proteção e melhoramento do meio ambiente;

c) o projeto deve ser economicamente viável. 


\subsection{Sobre o Conceito do Socialmente Justo}

Pegoraro (1995) afirma que a justiça ilumina, ao mesmo tempo, a subjetividade humana e a ordem jurídica e social. A justiça consiste em realizar uma sociedade como sistema equitativo de cooperação entre cidadãos livres e iguais. No final da apresentação encerra o texto com um belíssimo elogio tomado de Aristóteles: "A justiça é a virtude perfeita que nos relaciona com os semelhantes". ${ }^{4}$

J. Rawls na sua obra "Teoria da Justiça" pensa a ética como um esforço de superação de conflitos sociais produzidos pela disputa dos bens materiais e culturais. Como os bens são quantitativamente limitados, e sem limites o apetite de cada cidadão, torna-se necessária a intervenção de um princípio mediador. Este papel é exercido pelo princípio objetivo da justiça. Nesse sentido, ética é a prática da justiça, ou, comportamento ético é, antes de tudo, comportamento segundo a justiça. No entanto, ninguém é justo para si, mas em relação aos outros. Aqui a justiça manda reconhecer o outro como igual a mim, portador da mesma dignidade e direitos.

Considerando o elevadíssimo conceito da justiça legal, Aristóteles deduz duas modalidades de justiça particular: distributiva e comutativa. A primeira, que regula as ações da sociedade política em relação ao cidadão, tem como objetivo a justa distribuição dos bens públicos: hortas, riquezas, encargos sociais e obrigações. A segunda forma de justiça, a comutativa, regula as relações entre cidadãos. São as relações planejadas e voluntárias, como nos casos de contratos, compras e vendas, salários, empréstimos etc.

Em nossos dias, o pensador americano J. Rawls enfoca a justiça como base de um novo contrato social, na esteira de Kant e Rousseau. O tema central das obras deste autor é a justiça. Para evitar equívocos terminológicos e conceituais, convém afirmar, desde o início, que esta ideia não é tomada nem em sentido aristotélico e nem propriamente no sentido kantiano: a justiça não é uma virtude e nem um direito, mas sim um princípio fundador de uma sociedade bem ordenada.

Portanto, a partir da ideia de conflito social pode-se concentrar o movimento da ética-política segundo John Rawls em três tempos:

a) reconhecimento do conflito entre os bens disponíveis escassos e o desejo ilimitado de posse por parte dos indivíduos;

b) intervenção da teoria da justiça instaurando a sociedade bem ordenada e justa;

c) a consolidação da comunidade política onde prevalece a cooperação, o senso da justiça e as virtudes da cidadania.

Desde o princípio aparece com clareza a tese principal do tratado: "A justiça é a primeira virtude das instituições sociais como a verdade o é para os sistemas de pensamento". Não discute a justiça em termos doutrinários, mas a justiça como equidade aplicada à distribuição dos bens sociais. Esta é a função da justiça como equidade, que deve ser o imperativo categórico da sociedade política. Mesmo a liberdade, tão fundamental na filosofia política moderna, cai sob o império da justiça à qual cabe estabelecer-lhe os limites do exercício.

Dois são os princípios de justiça da sociedade bem ordenada, segundo J. Rawls:

1. Cada pessoa deve ter direito a uma liberdade de base mais larga possível, compatível com uma liberdade similar para todos os outros.

2. As desigualdades sociais e econômicas devem ser organizadas de tal modo que: a) se possa razoavelmente esperar que elas sejam vantajosas para todos; e b) sejam ligadas a posições e funções acessíveis a todos.

\footnotetext{
${ }^{4}$ Mais recentemente, Bahá 'u'lláh, mestre espiritual da humanidade, afirmou: "A meu ver, a mais amada de todas as coisas é a Justiça". (Comunidade Internacional Bahaí: 1995).
} 
O primeiro é o princípio da liberdade e dos direitos humanos fundamentais. Garante os direitos de participação política, de opinião, de reunião, de consciência, religião etc. Este é de fato o imperativo categórico da filosofia política de J. Rawls e o fundamento do estado de direito e da democracia constitucional.

O segundo é o princípio da diferença. .Refere-se aos interesses materiais, à repartição equilibrada dos bens primários, dos encargos, dos deveres e das vantagens sociais. Aqui, trava-se o debate com as teses marxistas e com o liberalismo ortodoxo. Contra as teses igualitárias, Rawls afirma que as desigualdades sociais intoleráveis no seio do primeiro princípio, não podem ser negadas na ordem social, econômica e cultural regida pelo segundo princípio. São aceitáveis desde que beneficiem os mais desfavorecidos na escala social. É preciso, que a sociedade, bem ordenada, maximize a condição mínima: uma vez aceito o princípio da diferença deduz-se que o mínimo social vital deve ser fixado num nível que maximize as expectativas dos grupos menos favorecidos.

\subsection{A Ordem Social Justa}

Pelo anteriormente exposto, o maior desafio contemporâneo é a construção de uma ordem social justa no plano local, nacional e internacional. Isto significa que é imperioso criar estruturas novas e abrangentes, de tal modo que as necessidades básicas dos seres humanos sejam satisfatoriamente preenchidas. Em síntese, é preciso que as estruturas sirvam ao bem humano.

O princípio da vida segundo a justiça pode ser assim enunciado: devemos respeitar os direitos básicos da vida. Este princípio exige uma atitude fundamental: reconhecimento que todos os seres humanos nascem meta fisicamente iguais. A natureza nos deu direito igual à vida, à educação, à vida saudável, à participação na vida política, à distribuição dos bens materiais e culturais que alimentam a vida. Estes direitos não se conquistam: são dados pelo nascimento. Esta é a ideia central de todos os códigos que proclamam os direitos humanos. Por exemplo, o código de direitos humanos da ONU é de certo modo, um tratado de ética e de justiça assinados por quase todas as nações.

O segundo princípio, da vida social justa, pode ser formulado assim: devemos criar uma ordem social onde a cidadania seja plena e universal. A cidadania, como conquista dos atores sociais, é o resultado da consciência política e da participação efetiva na luta para a construção de estruturas sociais justas.

De fato, enquanto existirem miséria, fome, epidemias generalizadas, analfabetos, sem-teto, sem terras, nossa sociedade, em sua estruturação, será injusta, porque excluirá dos benefícios humanos básicos à maioria da população. A carta constitucional pode ser excelente, mas permanece letra morta até que sua regulamentação e implementação não crie estruturas que atendam às demandas básicas da comunidade.

Ademais, o princípio da justiça social administra as desigualdades. Nascemos em países com trajetória histórica diferente. Portanto, as desigualdades são uma realidade irrecusável. Cabe ao princípio de justiça social administrar as desigualdades históricas. Mas, in limine, a justiça não admite que as desigualdades sejam injustas. A justiça social prescreve que a organização da sociedade crie estruturas que garantam a todos os cidadãos a oportunidade de desenvolver suas capacidades e de evoluir em suas condições históricas.

\section{Sobre o Conceito Economicamente Viável e Ecologicamente sustentável ${ }^{5}$}

A noção de desenvolvimento que se tornou hegemônica em nossa sociedade associou as ideias de progresso, bemestar, melhoria a um sentido evolutivo unilinear, onde os povos puderam ser classificados numa escala que vai do atraso ao progresso, do tradicional ao moderno ou ainda do subdesenvolvimento ao desenvolvimento.

\footnotetext{
${ }^{5}$ Grande parte das ideias aqui apresentadas encontram-se no artigo da ISABEL C. M. CARVALHO: "Os mitos do desenvolvimento sustentável” publicado na revista mensal: Política ambiental, Novembro-dezembro. 1991, Brasília, D.F.: IBASE.
} 
O ideal desenvolvimentista, que se afirma a partir dos anos cinquenta do século XX, é um caso exemplar em nossa história recente da concepção unilinear do desenvolvimento associado à afirmação do projeto capitalista contemporâneo; no contexto da guerra fria, constituiu-se num conjunto de ideias força que motivaram as políticas de desenvolvimento.

$\mathrm{O}$ adjetivo sustentável remete àquilo que está em perfeito equilíbrio, que se conserva sem desgaste e se mantém no tempo. Quando aplicado ao desenvolvimento transfere essas qualidades a um modo de organizar a vida social, criando a expectativa de uma sociedade sustentável, em plena consonância com a natureza, sem conflitos sociais que possam pôr em risco a sua reprodução. Assim, o desenvolvimento sustentável aparece como a boa nova, que pode dar a todos um futuro estável.

Embora se apresente com ares de uma nova utopia, prometendo revolucionar as relações entre os homens e destes com a natureza, o desenvolvimento sustentável é um conceito gerado dentro da esfera da economia, e é com esta referência que pensa o social. A novidade que traz é a incorporação da natureza dentro da cadeia de produção.

Enquanto na teoria econômica clássica a natureza não transformada pelo trabalho humano é sem valor, o desenvolvimento sustentável incorpora o que era considerado um bem livre, atribuindo-lhe um custo que passa a ser contabilizado na produção. A natureza passa a ser um bem de capital e nasce aí uma espécie de economia ecológica.

Como esclarece o Relatório Bruntland ${ }^{6}$, os custos ambientais só aparecem quando a capacidade assimilativa do meio ambiente é ultrapassada. A partir daí, não podem ser evitados e terão que ser pagos. Basicamente, há duas possibilidades: os custos podem ser externalizados, ou seja, transferidos para vários segmentos da sociedade sob a forma de custos por danos à saúde humana, à propriedade e aos ecossistemas ou, internalizados, isto é, pagos pela empresa.

O princípio do poluidor pagador está mais voltado a uma nova contabilidade ambiental do que ao direito de todos a um meio ambiente sadio e à qualidade de vida.

O mercado opera baseado no princípio da conversibilidade universal. Assim, ao contabilizar os bens naturais antes livres de valor comercial, toma esses bens e a qualidade de vida e a eles associada (pureza da água, do ar, silêncio, alimentos saudáveis, etc.) equivalentes a um valor em moeda. Desta maneira, podem ser ressarcidos no caso de sua destruição ou prejuízo. Sabemos quanto esse câmbio é perverso. A destruição da natureza, das fontes de vida e das populações que dependem destes recursos para sua sobrevivência é impagável.

O que se revela neste movimento é a hegemonia do discurso econômico, que se instaura cada dia mais como o lugar de produção de verdades e fórmulas científicas de organização e vida social. É necessário inverter a premissa que está na base do pensamento economicista, onde se trava a discussão sobre o desenvolvimento. A economia não deve ser tomada como a dimensão determinante do campo social, mas instituída por este: deve estar a serviço da sociedade. As alternativas para o futuro são escolhas que devem se dar fundamentalmente no campo social e na esfera da tomada de decisões.

O desenvolvimento que queremos é aquele onde os povos e os grupos sociais possam definir suas necessidades e construir uma gestão democrática da diversidade tendo em vista ao conjunto da sociedade. Pensando num eixo democrático pluralista, o desenvolvimento não seria mais a marcha de todos numa só direção, mas sim o reconhecimento e a articulação de diferentes formas de organização e demandas diferenciadas como bases para uma real sustentabilidade.

A capacidade de garantir a sobrevivência das gerações presentes e futuras dependerá da capacidade de construirmos um modelo rico em alternativas que possa enfrentar - com novas soluções - a atual crise sócio ambiental. Só a ampla participação da sociedade pode viabilizar esse modelo e, portanto, a democracia e o consenso quanto possíveis, serão medidas efetivas para promover a sustentabilidade.

É fundamental remeter o pensamento e a ação para além do paradigma econômico materialista, que durante tanto

${ }^{6}$ Nosso Futuro Comum, Comissão mundial sobre o meio ambiente e desenvolvimento. (WCED) Rio de Janeiro: FGV, 1987. 
tempo tornou sinônimos: desenvolvimento, riqueza, bem estar, progresso e transformação intensiva da natureza. Se quisermos de fato assegurar o direito à sobrevivência física, econômica, social e cultural das populações, bem como garantir as condições ambientais que são o substrato para a sustentação de toda a vida no planeta, é preciso construir um modelo de desenvolvimento que tenha sua razão de ser nas prioridades estabelecidas pelo conjunto da sociedade. Isto significa inverter a trajetória excludente do desenvolvimento que conhecemos e estender a condição de cidadão à maioria que vive à margem dos processos econômicos, culturais e políticos.

Na consideração do conceito de desenvolvimento como um processo fundamentalmente participativo, os indicadores econômicos como renda per capita, produto interno bruto ou as melhoras na infraestrutura de uma comunidade não resumem os aspectos centrais do assunto.

Nesta nova perspectiva o conceito de desenvolvimento está relacionado com bem-estar e qualidade de vida das populações e coloca a participação na tomada de decisões como uma questão essencial. A participação plena se faz possível através da organização das comunidades e do treinamento de seus recursos humanos; pré-requisito necessário para uma consulta bem sucedida que promova o bem-estar e a justiça social.

\section{Desenvolvimento Sustentável, Agenda 21 e Cidadania Mundial}

A agenda 21 é um programa de ação, baseado num documento de 40 capítulos, que constitui a mais ousada e abrangente tentativa já realizada de promover, em escala planetária, um novo padrão de desenvolvimento, conciliando métodos de proteção ambiental, justiça social e eficiência econômica.

Trata-se de um documento consensual para o qual contribuíram governos e instituições da sociedade civil de 179 países, cujo processo preparatório durou dois anos e culminou com a realização de Conferência das Nações Unidas sobre Meio Ambiente e Desenvolvimento - CNUMAD, em 1992, no Rio de Janeiro, também conhecida por ECO-92. Além da Agenda 21, resultaram desse processo quatro outros acordos: a Declaração do Rio, a Declaração de Princípios sobre o Uso das Florestas, o Convênio sobre a Diversidade Biológica e a Convenção sobre a Mudança Climática.

O desafio da ECO-92 foi o seguinte: criar, em escala planetária, um novo tipo de desenvolvimento, capaz de fomentar o progresso humano, não apenas em alguns lugares e por alguns anos, mas em todo o planeta e por tempo indeterminado. Esta tese, defendida pela comissão do meio-ambiente da ONU em 1982, comporta dois pré-requisitos:

a. a criação de uma tecnologia limpa e subordinada à expansão da vida:

b) derrubar o muro político, econômico, e técnico-científico que mantém as excessivas desigualdades tanto ao nível de cada país como no campo internacional.

Por sua vez, RIO +20 mostrou as dificuldades de assumir um compromisso sério de parte das grandes potências, maiores responsáveis pela poluição mundial, ao tempo que expressou uma maior preocupação da sociedade civil nesta questão vital. Nessa perspectiva, cabe destacar, a contribuição da Comunidade Internacional Bahaí (2012) ao colocar em consideração o conceito de guardiania, nestes termos: "Todos e cada um de nós somos os guardiães do planeta”.

\section{Considerações Finais}

Em primeiro lugar quero lembrar algumas das conclusões de Meadows (1978):

- "Estamos unanimemente convencidos de que uma emenda rápida e radical na situação mundial, atualmente desequilibrada e em perigosa deterioração, é a tarefa fundamental com que se defronta a humanidade."

- "Qualquer tentativa deliberada para atingir um estado de equilibrio racional e duradouro, através de medidas 
planejadas, e não por meio de acasos e catástrofes, deve ser fundamentada, em última análise, em uma mudança básica de valores e objetivos em níveis individuais, nacionais e mundiais."

A Comunidade Internacional Bahai (1995) explicita o aspecto distintivo da mudança assinalada por Meadows (1978) com as seguintes palavras:

O maior desafio que a comunidade mundial enfrenta é o de liberar os enormes recursos financeiros, técnicos, humanos e morais necessários ao desenvolvimento sustentável. Tais recursos somente serão liberados na medida em que os povos do mundo desenvolvam um profundo senso de responsabilidade pelo destino do planeta e pelo bemestar da inteira família humana. Este senso de responsabilidade somente poderá emergir da aceitação da unidade da humanidade. Sem esse tipo de ética global, as pessoas não poderão se tornar participantes ativos e construtivos no processo mundial de desenvolvimento sustentável.

Mais recentemente, uma importante observação contida no Resumo Executivo do Relatório de Riscos Globais (2021) do Foro Econômico Mundial deve ser levada em consideração para entender as mudanças em andamento e os cenários possíveis a curto e longo prazo da sociedade humana:

"O COVID-19 acelerou a quarta revolução industrial, expandindo a digitalização da interação humana, o comercio, a educação à distancia e o trabalho remoto. Essas mudanças transformaram a sociedade muito além da pandemia, com a promessa de importantes benefícios.....porém, também pode criar ou aumentar as desigualdades....Embora o salto digital tenho aberto oportunidades para alguns jovens, muitos deles estão iniciando suas vidas profissionais sem perspectivas...

Para encerrar, quero trazer a tona a COP26 -conferência das Nações Unidas sobre mudanças climáticas- realizada neste ano de 2021 em Glasgow, na Escócia. Dito evento reafirma -uma vez mais- a preocupação crescente da sociedade civil e das lideranças de muitos países com a dramática situação do aquecimento global que a humanidade deve encarar nos próximos anos. É importante reconhecer que importantes esforços ao nível educacional, da tecnologia e das práticas de produção, assim como o incremento no uso de fontes de energia limpas tem sido realizados nas últimas décadas. No entanto, a humanidade ainda não conseguiu contornar a alarmante situação do nosso lar comum: o planeta terra.

\section{Referências}

Araújo, W. (2000). Quem está escrevendo o futuro? Letraviva.

Arbab, F. (1986). El proceso de transformación social. Fundaec.

Arbab, F. (1985). Universidad Rural: aprendizaje sobre educación y desarrollo.CIID.

Arenas, PAR. (2019). Textos para um novo contexto. DUERN.

Aron, R. (1993). As etapas do pensamento sociológico. Martins Fontes.

Berman, M. (1982). Tudo que é sólido desmancha no ar: a aventura da modernidade. Companhia das Letras.

Bourdieu, P. (1994). Sociologia. Ática.

Brandão, DMS. (1991). O Novo Paradigma Holístico. Summus.

Capra, F. (1995). O Ponto de Mutação. Cultrix.

Capra, F. (2012) A teia da vida. - Uma Nova Compreensão Científica dos Sistemas Vivos. Cultrix

Capra, F. (2013). Alfabetização Ecológica. São Paulo: Cultrix.

Carvalho, ICM. (1991). Os mitos do desenvolvimento sustentável. In: Revista Política Ambiental.

Castells, M. (2000). Fim de Milênio, A era da informação: Economia, Sociedade e Cultura.: Paz e Terra.

Comunidade Internacional Bahai. (1995). A Cidadania Mundial: uma ética global para o desenvolvimento sustentável. Bahaí. 
Comunidade Internacional Bahai. (2012) Sociedades sustentáveis rumo a um novo nós. Declaração da CIB para a Conferência das Nações Unidas sobre Desenvolvimento Sustentável. RIO + 20. Disponível em: https: www.bahai.org.br.

Cotrim, G. (1999). Historia e Consciência do mundo. Saraiva.

Daltro, M R., Faria, AA. (2019). Relato de experiência: Uma narrativa científica na pós-modernidade. Estudos e pesquisas em psicologia, $19(1), 223-237$.

Fanon, F. (1971). Los condenados de la tierra. México: Fondo de Cultura Económica, 1971.

Fatheazam, S. (2015). The Last Refuge. Wilmette, Illinois, USA.

Friedman, T L. (2014). O mundo é plano - uma breve história do século XXI. Companhia das Letras.

Freire, P. (2014). Extensão ou comunicação. Paz e Terra.

Fundação Getúlio Vargas. (1979). Dicionário de Ciências Sociais. FGV.

Galeano, E. (1979). As veias abertas da América Latina. Paz e Terra.

Gorz, A. (1977). Écologie et Liberté. Paris: Galilée.

Gorz, A. (2003). Metamorfoses do Trabalho - Busca do sentido, Crítica da Razão Econômica. Trad. Ana Montoia. Annablume.

Gil, A. C. (2002). Como elabora projetos de pesquisa. (4a ed.) Atlas.

Harari, Y. N. (2020). Sapiens: uma breve história da humanidade. $L \& M$.

Henderson, H. (1997). Locking back from the 21st Century. In: Futures Bulletin, World Futures Studies Federation. Brisbane (Austrália) 23(1).

Krenak, A. (2019). Ideias para adiar o fim do mundo. Companhia das Letras.

King, A. (1991). The First Global Revolution. Pantheon Books.

Kuhn, T. (1994) A Estrutura das Revoluções Científicas. Perspectiva.

Kurz, R. (1992). O Colapso da Modernização. Paz e Terra.

Marx, K. \& Engels, F. (1998). Manifesto do Partido Comunista. Global.

Meadows, D. (1978). Limites do Crescimento. Perspectiva.

Morin, E. (2001). As sete saberes necessários à educação do Futuro. Cortez, Unesco.

Naisbitt, J. (1990). Megatendências 2000. Amana Key.

Naisbitt, J. (1994). Paradoxo Global. Campus.

Neme, F. (2010). Comunidade Sustentável. Editora Bahá'i, 2010

Ortiz, R. (2000). Mundialização e Cultura. Brasiliense.

Pegoraro, O. (1995). Ética é justiça. Vozes.

Rawls, J. (1971). A Theory of Justice. Cambrigde: Mass.

Rictha. R. (1977). La Civilización en la Encrucijada. Siglo XXI.

Singer, P. (1981). O qué o Socialismo hoje? P: Vozes.

Sweesy, P., \& Baran P. (1973). El Capital Monopolista. Siglo XXI.

Toffler, A. (1980). A terceira onda. Record.

Valcárcel, F. T., \& Lizcano, G. C. (1995). Salvar as barreras. FUNDAEC.

Ware, C. (1982). Historia de la humanidad. El Siglo XX. Vol. 10-12 Planteta.

World Economic Forum, (2021). Relatório de Riscos Globais. 16 Edição. Pág. 3 Suíça, 2021

Weber, M. (1967). A ética protestante e o espírito do capitalismo. Pioneira.

Zeman, Z. P. (1997). Restructuring for the $21^{\text {st }}$ Century. In: Papers de prospectiva, N. ${ }^{\circ}$ 6. Centre Catalá de Prospectiva. 